\title{
DOCUMENTOS
}




\section{EL SALTO EDUCATIVO}

\section{EDUCACIÓN: EJE DEL DESARROLLO DEL PAIS}

Creemos que las condiciones están dadas como nunca para el cambio social, y que la educación será un órgano maestro. Una educación de la cuna hasta la tumba, inconforme y reflexiva, que nos inspire un nuevo modo de pensar y nos incite a descubrir quiénes somos en una sociedad que se quiera más a sí misma. Que aprovecha al máximo nuestra creatividad inagotable y conciba una ética -y tal vez una estética- para nuestro afán desaforado y legítimo de superación personal... Por el país próspero y justo que soñamos: al alcance de los niños.

\section{Gabriel García Márquez Misión Ciencia, Educación y Desarrollo}

\section{CONTEXTO}

La educación debe ser el eje fundamental del desarrollo económico, político y social de la Colombia de hoy y del futuro. Además del valor intrínseco que tiene una sociedad más educada, por medio de la educación se apropia, crea y difunde el progreso científico y tecnológico, y se construye y transmite una ética de convivencia y equidad que es sustento del desarrollo integral de una nación.

La educación debe contribuir al propósito nacional de formar un nuevo ciudadano "más productivo en lo económico, más solidario en lo social, más participativo y tolerante en lo político: más respetuoso de los derechos humanos y por tanto más pacífico en sus relaciones con sus semejantes; más consciente del valor de la naturaleza y por tanto, menos depredador, integrado en lo cultural y por tanto más orgulloso de ser colombiano".

En este sentido, los nuevos sistemas educativos deberán permitir que el conocimiento se genere y se expanda fácilmente, haciendo del aprendizaje y no de la enseñanza, la esencia de la educación. Para ello será indispensable que el estudiante sea el centro de atención de la política educativa y que la institución educativa se convierta en el centro de la actividad administrativa y organizacional.

\section{DIAGNÓSTICO}

\section{A. Gasto educativo y equidad}

El gasto público en educación ha tenido en Colombia una tendencia levemente ascendente aunque sujeta a fuertes fluctuaciones cíclicas. Su participación en el PIB aumentó del $2.85 \%$ en la década de los 70 al $2.99 \%$ en los años 80 y $3.07 \%$ en 1993 . Este nivel es inferior al de muchos países latinoamericanos con nivel de desarrollo similar (ver cuadro No. 1).

\footnotetext{
“Documento CONPES 2738 -MINEDUCACION- DNP: UDS. Santafé de Bogotá, D.C.. Octubre 19 de 1994 
En su composición, el gasto educativo muestra desequilibrios significativos en cuanto a los niveles a los cuales está dirigido: en 1994 la participación de la educación primaria alcanzó el $31 \%$, la secundaria el $28 \%$, y la educación superior el $19 \%$. Los gastos por estudiante son menores frente a otros países latinoamericanos, especialmente para primaria y secundaria. El gasto por estudiante en educación superior es doce veces más elevado que el de primaria, una de las relaciones más altas para países con similares niveles de desarrollo (ver cuadro No. 2).

Esta composición no refleja los efectos redistributivos de distintos tipos de gasto en educación. En efecto, el gasto en primaria es progresivo: el 40\% más pobre de la población recibe el $67 \%$ del subsidio en este nivel. En secundaria es algo menos progresivo (el $40 \%$ más pobre recibe el $46 \%$ de los subsidios), pero con la ampliación de la cobertura tiende a hacerse cada vez más favorable el efecto redistributivo de dicho gasto. Por el contrario, el gasto en educación superior es regresivo, ya que el $40 \%$ más pobre sólo recibe el $15 \%$ de los subsidios correspondientes.

Cuadro No. 1

\section{GASTO PÚBLICO EN EDUCACIÓN COMO PORCENTAJE DEL PIB 1990}

\begin{tabular}{|l|c|}
\hline \multicolumn{1}{|c|}{ PAISES } & PORCENTAJE \\
Uruguay & 3.1 \\
Chile & 3.7 \\
Costa Rica & 4.6 \\
Venezuela & 4.1 \\
Panamá & 5.5 \\
Colombia (1993) & 3.1 \\
México Con Desarrollo Humano medio & 4.1 \\
\multicolumn{1}{|c|}{ Brasil } & \\
Ecuador & 4.6 \\
Suriname & 2.8 \\
Cuba & 8.3 \\
Perú & 6.6 \\
Rep. Dominicana & 2.3 \\
Guatemala & 2.1 \\
El salvador & 1.4 \\
Bolivia & 1.8 \\
Honduras $\quad 3.0$ \\
Industrializados (1991) & 4.6 \\
Canadá & 7.4 \\
Japón & 5.0 \\
Francia & 6.0 \\
Estados Unidos & 7.0 \\
Alemania & 5.4 \\
Dinamarca & 6.1 \\
España & 5.6 \\
Noruega & 7.6 \\
\hline \multicolumn{2}{|l}{} \\
\hline
\end{tabular}

Fuente:PNUD, Informe sobre Desarrollo Humano, 1994 


\section{Cuadro No. 2
GASTO POR ESTUDIANTE SEGÚN NIVEL (US\$)}

\begin{tabular}{|l|c|c|c|c|c|}
\hline \multicolumn{1}{|c|}{ País } & Año & Primaria & Secundaria & Superior & $\begin{array}{c}\text { Superiorl } \\
\text { Primaria }\end{array}$ \\
Argentina & 1985 & 142 & 310 & 577 & 4.1 \\
Bolivia & 1990 & 72 & 101 & 504 & 7.0 \\
Brasil & 1989 & 243 & 434 & 5.911 & 24.3 \\
Chile & $1987 / 93$ & 181 & 363 & 1.006 & 5.6 \\
Colombia & 1990 & 92 & 183 & 1.086 & 11.9 \\
Costa Rica & 1986 & 144 & 322 & 1.541 & 10.7 \\
Ecuador & 1987 & 97 & 218 & 652 & 6.7 \\
El Salvador & 1990 & 63 & 66 & 227 & 3.6 \\
Honduras & 1990 & 15 & 185 & 1.233 & 10.8 \\
México & 1984 & 135 & 589 & 1.035 & 7.7 \\
Paraguay & 1990 & 50 & 144 & 710 & 14.2 \\
Uruguay & 1989 & 256 & 306 & 614 & 2.4 \\
Venezuela & 1989 & 198 & 347 & 1.625 & 8.2 \\
\hline
\end{tabular}

Fuente:World Bank. Colombia Poverty Assessment Report. August. 1994. Para Colombia, gastos unitarios de C. G. Molina et. al. (1993).

\section{B. La Educación Básica}

Aunque Colombia ha realizado esfuerzos importantes para universalizar la educación primaria y ampliar la cobertura de la educación secundaria ${ }^{1}$, el objetivo de una Educación Básica universal, consagrado en la Constitución de 1991, dista todavía mucho de ser una realidad. En la actualidad, la cobertura neta de la educación primada es del $85 \%$ y aunque persisten problemas de acceso a este nivel, la dificultad más grave es la inadecuada retención del estudiante en el sistema, particularmente para los niños de familias de bajos ingresos. Por otra parte, 2.4 millones de niños y jóvenes entre 12 y 17 años de edad no están escolarizados, siendo la cobertura de la educación secundaria particularmente baja en las zonas rurales y en los grupos de población de menores ingresos ${ }^{2}$.

Los logros recientes en aumento de cobertura se han visto contrarrestados por la baja eficiencia interna del sistema. De cien niños que inician el primer grado de primaria, 60 terminan quinto grado y sólo 40 de ellos lo hacen en cinco años. Las altas tasas de repitencia ( $25.5 \%$ en el primer grado) se traducen, a su vez, en una tasa de deserción escolar cercana al $35 \%$ en los tres primeros años. Así mismo, de cada 100 niños que entran a primer grado, únicamente 30 culminan la Educación Básica (lo. a 9o. grados) y de ellos sólo siete lo hacen sin repetir año (ver cuadro No. 3).

La deficiente calidad de la educación explica estos problemas de eficiencia. La calidad de la educación en Colombia está lejos de ser satisfactoria. Los resultados de pruebas de conocimiento en matemáticas y lenguaje muestran que los estudiantes fallan precisamente en aquellas habilidades que son fundamentales para seguir aprendiendo ${ }^{3} \mathrm{y}$ que la calidad de la educación se ha deteriorado en los últimos años ${ }^{4}$.

\footnotetext{
${ }^{1}$ El Plan de Fomento para la Educación en Zonas Rurales, el Plan de Universalización de la Educación Primaria y el Plan de Ampliación de la Calidad de la Educación Secundaria (PACES). El modelo Escuela Nueva ha permitido también mejorar la cobertura de la educación primada en las áreas rurales del país.

${ }^{2}$ La cobertura para el primer quintil de la población es la mitad de aquella del quintil más alto. Molina, C.G,. 1993.

${ }^{3}$ En matemáticas, los estudiantes logran resolver algoritmos usuales, pero fallan en la resolución de problemas, particularmente si estos implican varias operaciones. En lenguaje, logran decodificar los signos que constituyen el texto y encontrar información explícitamente enunciada. Sin embargo muestran 
Las características del plantel y las de los procesos pedagógicos son las variables que más pesan en la explicación del rendimiento de los estudiantes. Esto indica que el sistema educativo tiene en sus manos las principales herramientas para mejorar la calidad de la educación. En efecto, docentes calificados, planteles bien dotados, estudiantes con textos y una mayor jornada, están asociados positiva y significativamente con el logro de los estudiantes. Este último factor es particularmente relevante si se tiene en cuenta que en Colombia se reciben en promedio 680 horas de clase al año, contra 1.100 en Estados Unidos, 1.200 en Corea, 1.300 en Europa y 1.500 en Japón.

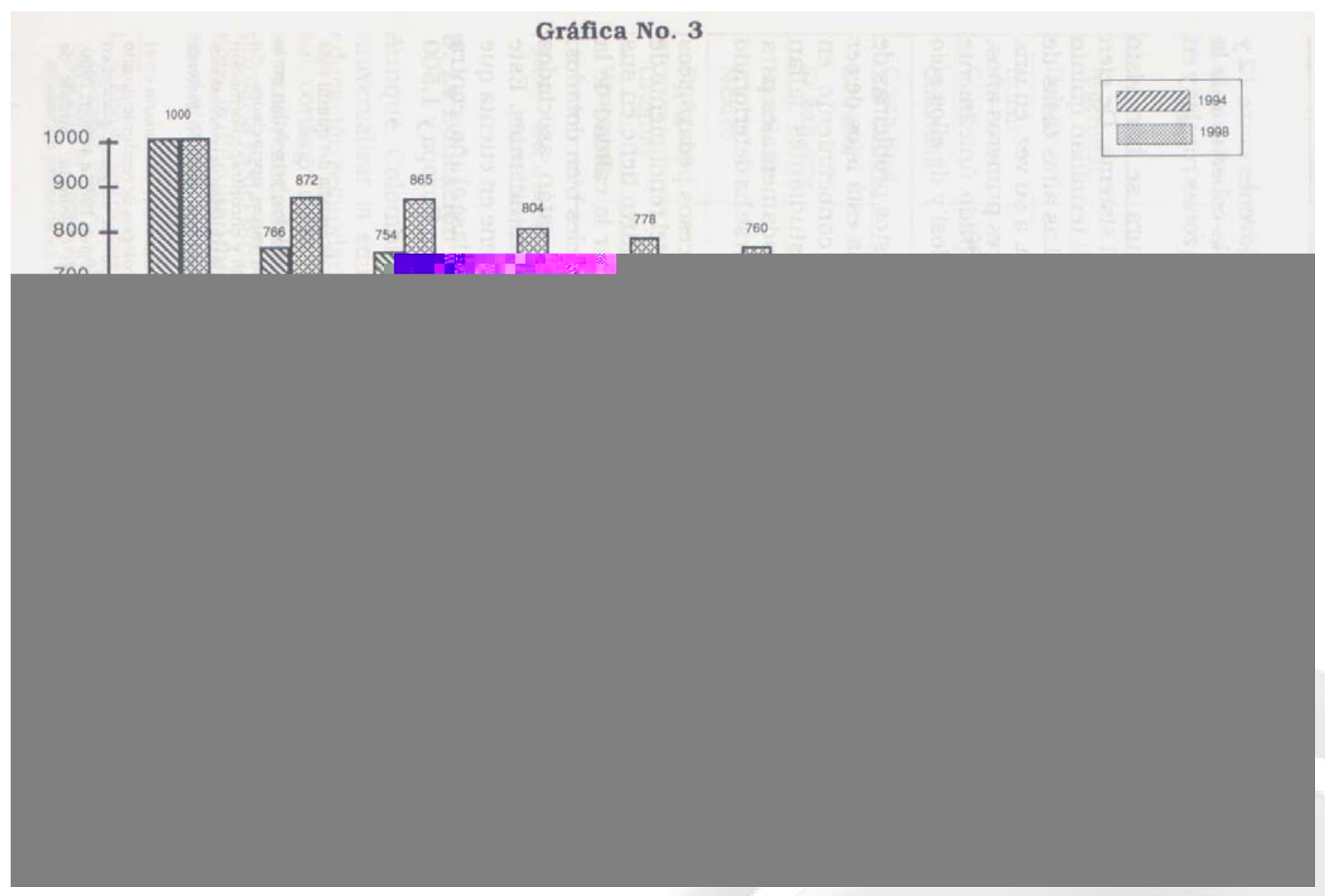

Los problemas señalados son más agudos en algunas regiones del país. Las deficiencias en cobertura son más pronunciadas en regiones como la Costa Pacífica, la Costa Atlántica y, en general, en las zonas rurales. La calidad de la educación muestra también desequilibrios significativos, tanto entre zonas urbanas y rurales como entre planteles públicos y privados, con diferencias notables entre las distintas regiones (ver gráficas 1 y 2 ).

\footnotetext{
deficiencias en la educción de conclusiones y la elaboración de inferencias. Ministerio de Educación Nacional. SABER. Sistema Nacional de Evaluación de la calidad de la Educación, 1992.

${ }^{4}$ A partir de 1985 se ha presentado un deterioro relativo de la educación secundaria en el país, particularmente en el sector oficial. Aunque el número de colegios de rendimiento alto ha permanecido relativamente estable, se observa una reducción de su participación en el total debido al aumento de colegios de rendimiento bajo, del $34 \%$ en 1985 a $46 \%$ en 1990. FEDESARROLLO. calidad de la Educación Secundaria en Colombia. Santafé de Bogotá, 1991.
} 

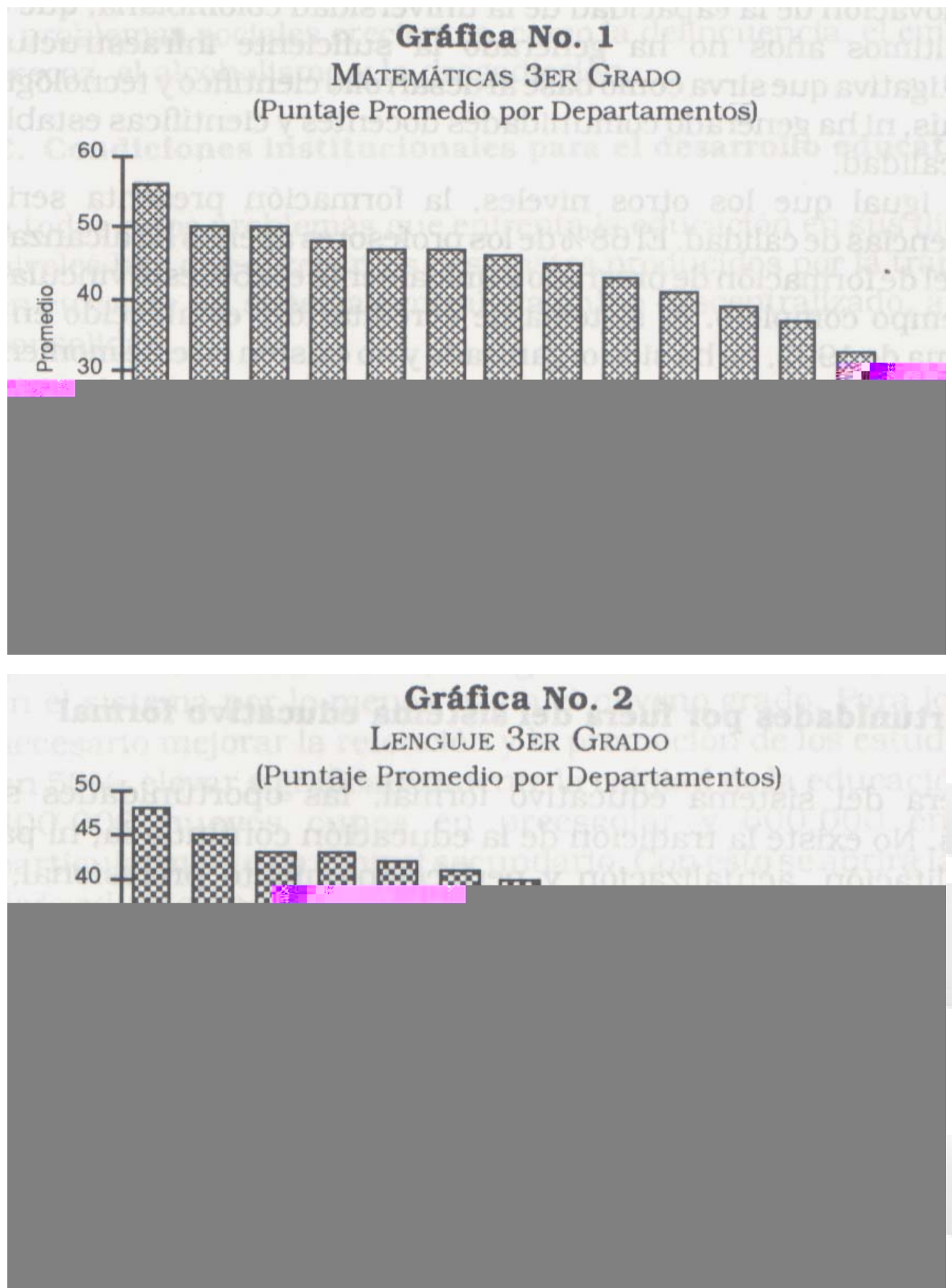

\section{Fuente: SABER}

\section{La Educación Superior}

La universidad juega un papel fundamental en las sociedades modernas, mediante la formación de capital humano para enfrentar los retos del desarrollo científico y tecnológico así como la producción, evaluación, transferencia y difusión del conocimiento. 
Los retos nacionales en los campos económicos y sociales exigen la renovación de la capacidad de la universidad colombiana, que en los últimos años no ha generado la suficiente infraestructura investigativa que sirva como base al desarrollo científico y tecnológico del país, ni ha generado comunidades docentes y científicas estables y de calidad.

Al igual que los otros niveles, la formación presenta serias deficiencias de calidad. El $68 \%$ de los profesores apenas ha alcanzado el nivel de formación de pregrado y únicamente el $25 \%$ está vinculado de tiempo completo. El sistema de acreditación, establecido en la reforma de 1992, no ha sido organizado y no existen en este momento mecanismos que permitan evaluar la calidad de oferta educativa, máxime cuando, a raíz de la citada reforma, la autonomía institucional ha permitido que aparezcan una serie de programas nuevos cuya calidad es incierta.

El acceso a la educación superior tiene a su vez dos problemas fundamentales: la insuficiente cobertura ${ }^{5}$ y una inequitativa distribución de la matrícula, puesto que el $83 \%$ de ésta pertenece al $40 \%$ de la población de mayores ingresos.

\section{Oportunidades por fuera del sistema educativo formal}

Por fuera del sistema educativo formal, las oportunidades son escasas. No existe la tradición de la educación continuada, ni para la habilitación, actualización y perfeccionamiento profesional, ni tampoco para el desarrollo de habilidades y aptitudes más allá de las adquiridas en la Educación Básica.

Anualmente egresan de secundaria 295.000 jóvenes, de los cuales sólo el 25\% pasa al nivel superior. Del $75 \%$ restante, la mayoría ingresa al mercado laboral y un número limitado busca alternativas en la educación no formal (capacitación para el trabajo), cuya oferta es insuficiente y de baja calidad. Esta situación genera una importante población de bachilleres desempleados (10.9\% en 1992). A esto se suman miles de jóvenes desertores del sistema escolar, para quienes las oportunidades educativas y laborales son restringidas por su baja escolaridad.

Las limitaciones mencionadas se agravan con la ausencia de oportunidades recreativas y culturales, en particular para los niños y jóvenes, que no encuentran actividades atractivas para el uso del tiempo libre. El uso inadecuado de éste por los jóvenes ha dado auge a problemas sociales crecientes, como la delincuencia, el embarazo precoz, el alcoholismo y la drogadicción.

\section{E. Condiciones institucionales para el desarrollo educativo}

A todos estos problemas que enfrenta la educación en sus distintos niveles hay que agregar los desajustes producidos por la transición en curso de un sistema centralista a uno descentralizado, aún por consolidar.

\section{OBJETIVOS Y METAS DEL PLAN}

1. Generar una movilización nacional de opinión en torno a la importancia de la calidad de la educación que permita que este tema sea acogido, discutido y promovido por todos y cada uno de los estamentos de la sociedad.

\footnotetext{
${ }^{5}$ La tasa de escolarización -11.5\%- es similar a la de México y Brasil pero muy inferior a la de chile y Venezuela $-23 \%$ y $30 \%$, respectivamente. 
2. Elevar el promedio de escolaridad de los colombianos, buscando que todos los estudiantes que ingresan a la educación permanezcan en el sistema por lo menos hasta el noveno grado. Para lograrlo es necesario mejorar la retención y la promoción de los estudiantes en un $50 \%$, elevar significativamente la calidad de la educación y crear 300.000 nuevos cupos en preescolar y 600.000 en básica, particularmente en el nivel secundario. Con esto se abrirá la frontera de la educación secundaria a miles de estudiantes que hoy no tienen acceso a este nivel y se elevará el promedio de escolaridad de 5.5 a 6.9 años (ver gráfica No. 3).

Como resultado de las intervenciones previstas en el plan, se espera que en 1998 ingresen al 9o. grado 483.000 estudiantes, esto es, 132.000 adicionales a los que habrían ingresado de mantenerse las tendencias actuales de retención y promoción (ver cuadros Nos. 4 y 5). En el cumplimiento de estos objetivos, la inversión en Educación Básica se elevará a $\$ 718.000$ millones que, sumados a los recursos del funcionamiento, incrementarán la participación en el PIB de $2.33 \%$ a $3.04 \%$ en este nivel, lo que representa un crecimiento real del gasto de más del $63 \%$ frente al periodo anterior (ver cuadros Nos. 6 y 7 ). 
Cuadro No. 3

TRAYECTORIA Y EFICACIA DE UNA COHORTE DE EDUACION BASICA

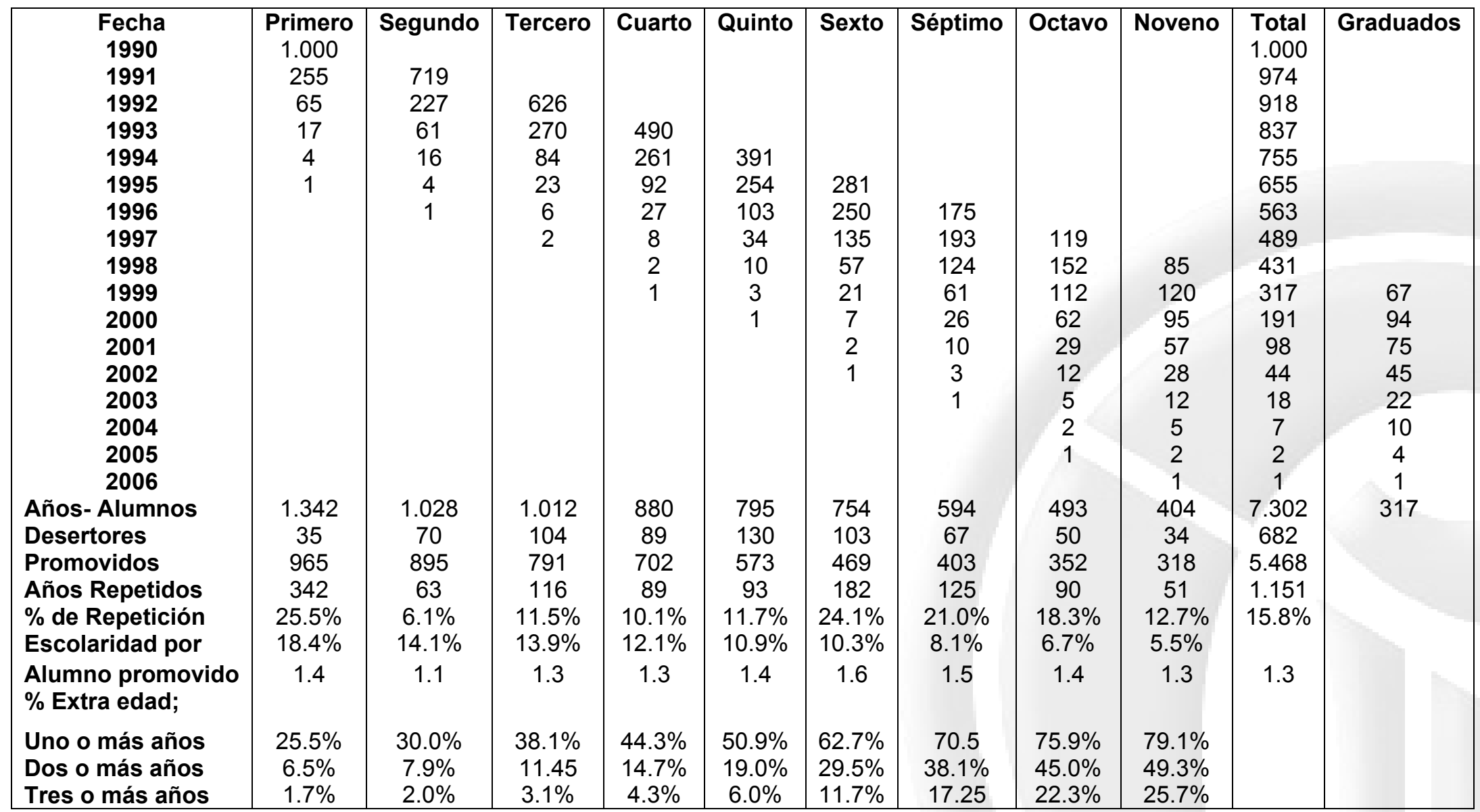




\section{RESUMEN DE PROMEDIOS OBSERVADOS EN EL SISTEMA ESCOLAR}

Años alumnos que le toma al sistema en promedio cada graduado:

Años que cada alumno permanece en educación básica (escolaridad media):

Grados que aprueba cada alumno en su paso por la escuela:

\section{Cuadro No. 4}

VARIACION DE MATRICULA 1994-1998

\begin{tabular}{|c|c|c|c|}
\hline $\begin{array}{ll} & \text { Año } \\
1994 & \\
1995 & \\
1996 & \\
1997 & \\
1998 & \end{array}$ & $\begin{array}{c}\text { Primaria } \\
4.529 .359 \\
4.677 .416 \\
4.570 .397 \\
4.551 .640 \\
4.491 .880\end{array}$ & $\begin{array}{c}\text { Secundaria } \\
2.065 .711 \\
2.115 .297 \\
2.346 .937 \\
2.516 .435 \\
2.741 .624\end{array}$ & $\begin{array}{c}\text { Total } \\
6.595 .071 \\
6.792 .713 \\
6.917 .334 \\
7.068 .075 \\
7.233 .504\end{array}$ \\
\hline Grado & 1994 & 1998 & Variación \\
\hline Preescolar & 506.080 & 806.080 & 300.000 \\
\hline Primero & 1.404 .347 & 1.074 .705 & (329.642) \\
\hline Segundo & 968.480 & 926.234 & $(42.246)$ \\
\hline Tercero & 847.379 & 899.000 & 51.626 \\
\hline Cuarto & 710.314 & 819.237 & 108.923 \\
\hline Quinto & 598.839 & 772.698 & 173.860 \\
\hline Sexto & 740.407 & 881.002 & 140.595 \\
\hline Séptimo & 537.322 & 731.722 & 194.400 \\
\hline Octavo & 436.994 & 645.863 & 208.869 \\
\hline Noveno & 350.987 & 483.036 & 132.049 \\
\hline Total Ed. Básica & 6.595 .071 & 7.233 .504 & 638.434 \\
\hline Total & 7.101.152 & 8.039 .584 & 938.434 \\
\hline $\begin{array}{l}\text { Población 5-15 } \\
\text { Cobertura Bruta }\end{array}$ & $\begin{array}{c}8.678 .779 \\
81.82 \%\end{array}$ & $\begin{array}{c}8.989 .242 \\
89.44 \%\end{array}$ & $\begin{array}{c}310.463 \\
7.61 \%\end{array}$ \\
\hline
\end{tabular}

Fuente: MEN - Subdirección de Análisis y Desarrollo de la Información Educativa.

Población: Cálculos DNP - UDS - DEC 
Cuadro No. 5

TASAS DE PROMOCION, DESERCION Y REPETICION 1991

\begin{tabular}{|c|c|c|c|}
\hline Grados & Repetición & Deserción & Promoción \\
1 & $25.5 \%$ & $2.6 \%$ & $71.9 \%$ \\
2 & $6.1 \%$ & $6.8 \%$ & $87.1 \%$ \\
3 & $11.5 \%$ & $10.3 \%$ & $78.2 \%$ \\
4 & $10.1 \%$ & $10.1 \%$ & $79.8 \%$ \\
5 & $11.7 \%$ & $16.3 \%$ & $72.0 \%$ \\
6 & $24.1 \%$ & $13.7 \%$ & $62.2 \%$ \\
7 & $21.0 \%$ & $11.2 \%$ & $67.8 \%$ \\
8 & $18.3 \%$ & $10.2 \%$ & $71.5 \%$ \\
9 & $12.8 \%$ & $8.5 \%$ & $78.7 \%$ \\
\hline
\end{tabular}

Fuente: MEN - Oficina Sectorial de Planeación 1991

TASAS DE PROMOCION, DESERCION Y REPETICION 1998

\begin{tabular}{|c|c|c|c|}
\hline Grados & Repetición & Deserción & Promoción \\
1 & $14.3 \%$ & $1.5 \%$ & $84.2 \%$ \\
2 & $3.4 \%$ & $3.8 \%$ & $92.7 \%$ \\
3 & $6.5 \%$ & $5.8 \%$ & $87.7 \%$ \\
4 & $5.7 \%$ & $5.7 \%$ & $88.6 \%$ \\
5 & $8.3 \%$ & $9.2 \%$ & $82.5 \%$ \\
6 & $16.2 \%$ & $7.7 \%$ & $76.1 \%$ \\
7 & $14.4 \%$ & $6.3 \%$ & $79.3 \%$ \\
8 & $12.9 \%$ & $5.7 \%$ & $81.3 \%$ \\
9 & $8.1 \%$ & $4.8 \%$ & $87.1 \%$ \\
\hline
\end{tabular}

Cálculos: DNP - UDS - DEC. 
PRESUPUESTO DE FUNCIONAMIENTO E INVERSION DEL SECTOR CENTRAL POR NIVELES EDUCATIVOS

Fuentes:

Informes financieros Contraloría General de la República (1990-1993)

\begin{tabular}{|c|c|c|c|c|c|c|c|c|c|}
\hline FUNCIONAMIENTO & $\begin{array}{c}1990 \\
1.001 .519\end{array}$ & $\begin{array}{l}1991 \\
972.704\end{array}$ & $\begin{array}{c}1992 \\
1.528 .244\end{array}$ & $\begin{array}{c}1993 \\
1.372 .511\end{array}$ & $\begin{array}{c}1994 \\
1.579 .822\end{array}$ & $\begin{array}{c}1995 \\
1.780 .564\end{array}$ & $\begin{array}{c}1996 \\
1.971 .245\end{array}$ & $\begin{array}{c}1997 \\
2.169 .484\end{array}$ & $\begin{array}{c}1998 \\
2.346 .176\end{array}$ \\
\hline Primaria (1) & 393.676 & 388.059 & 468.373 & 496.373 & 613.626 & 641.478 & 728.253 & 771.164 & 826.093 \\
\hline Secundaria (2) & 309.797 & 320.007 & 376.838 & 419.837 & 522.718 & 546.444 & 620.364 & 656.917 & 703.709 \\
\hline Otras Transferencias a Dtos. (3) & & & & & & 38.000 & 67.431 & 185.651 & 260.066 \\
\hline Superior (4) & 207.180 & 207.715 & 221.016 & 247.896 & 265.728 & 293.534 & 293.828 & 294.122 & 294.416 \\
\hline MEN-DS (5) & 67.237 & 30.459 & 429.829 & 183.831 & 139.747 & 224.661 & 224.886 & 225.111 & 225.336 \\
\hline Otros (6) & 23.628 & 26.464 & 31.583 & 24.573 & 38.003 & 36.446 & 36.483 & 36.519 & 23.556 \\
\hline \% P.I.B. & $2.22 \%$ & $2.11 \%$ & $3.20 \%$ & $2.73 \%$ & $2.99 \%$ & $3.20 \%$ & $3.35 \%$ & $3.51 \%$ & $3.57 \%$ \\
\hline$\%$ P.I.B. (Pri + Sec) & $1.56 \%$ & $1.54 \%$ & $1.77 \%$ & $1.82 \%$ & $2.15 \%$ & $2.20 \%$ & $2.41 \%$ & $2.61 \%$ & $2.72 \%$ \\
\hline INVER & 123.900 & 186.432 & 174.275 & 169.413 & 348.028 & 469.153 & 642.963 & 760.670 & 858.206 \\
\hline Prim & 20.850 & 28.154 & 28.606 & 51.341 & 38.477 & 46.637 & 85.345 & 96.295 & 101.954 \\
\hline laria (9) & 2.838 & 25.100 & 29.736 & 22.005 & 53.174 & 67.151 & 95.734 & 121.088 & 103.740 \\
\hline Superior (4) & 60.593 & 72.133 & 27.878 & 27.359 & 57.095 & 88.894 & 110.907 & 111.270 & 121.076 \\
\hline Otros (6) & 18.070 & 15.902 & 15.761 & 21.142 & 46.281 & 55.201 & 69.152 & 70.280 & 71.051 \\
\hline Transferencias a Mpios. (10) & 21.548 & 45.142 & 72.293 & 47.567 & 153.002 & 211.270 & 281.825 & 361.737 & 460.385 \\
\hline \% P.I.B. & $0.27 \%$ & $6.1 \%$ & $0.36 \%$ & $0.34 \%$ & $0.66 \%$ & $0.84 \%$ & $1.09 \%$ & $1.23 \%$ & $1.31 \%$ \\
\hline \% P.I.B. (Pri + Sec) & $0.05 \%$ & $2.0 \%$ & $0.12 \%$ & $0.15 \%$ & $0.17 \%$ & $0.20 \%$ & $1.031 \%$ & $0.35 \%$ & $0.31 \%$ \\
\hline TOT & 1.125 .418 & 1.159 .136 & 1.702 .519 & 1.541 .924 & 1.927 .850 & 1.249 .717 & 2.614 .208 & 2.930 .153 & 3.204 .382 \\
\hline Prin & 414.526 & 416.213 & 497.584 & 547.714 & 652.103 & 708.635 & 850.010 & 967.710 & 1.068 .483 \\
\hline daria & 312.636 & 345.107 & 406.574 & 441.841 & 575.892 & 631.075 & 747.116 & 863.404 & 927.079 \\
\hline Superior & 267.774 & 279.848 & 248.804 & 275.255 & 322.823 & 382.428 & 404.735 & 405.392 & 415.492 \\
\hline MEN-DS & 67.237 & 30.459 & 429.829 & 183.831 & 139.747 & 224.661 & 224.886 & 225.111 & 225.336 \\
\hline Otros & 41.698 & 42.367 & 47.345 & 45.716 & 84.283 & 91.648 & 105.635 & 106.799 & 107.607 \\
\hline Transferencias a Mpios. (10) & 21.548 & 45.142 & 72.293 & 47.567 & 153.002 & 211.270 & 281.825 & 361.737 & 460.385 \\
\hline \% P.I.B. & $2.50 \%$ & $2.52 \%$ & $3.56 \%$ & $3.07 \%$ & $3.65 \%$ & $4.04 \%$ & $4.44 \%$ & $4.74 \%$ & $4.88 \%$ \\
\hline$\%$ P.I.B. (Pri + Sec) & $1.61 \%$ & $1.66 \%$ & $1.89 \%$ & $1.97 \%$ & $2.33 \%$ & $2.41 \%$ & $2.71 \%$ & $2.96 \%$ & $3.04 \%$ \\
\hline PIB & 45.098 .521 & 46.001 .216 & 47.763 .610 & 50.282 .594 & 52.796 .733 & 55.700 .545 & 58.842 .038 & 61.860 .673 & 65.720 .728 \\
\hline
\end{tabular}

Ley de Presupuesto, apropiación vigente 1994, con ejecución proyectada del 93\%, excepto Situado Fiscal y Transferencias a municipios Proyecto General de Presupuesto de 1995 para los datos de Funcionamiento Superior, MEN-DS y Otros, con ejecución proyectada del 93\% Inversión de 1995 según Costos del Plan de Desarrollo, proyectos nuevos y antiguos.

Cálculos DNP, (UMACRO, UDT, UDS-DEC) 1996-1998, incluye Costos del Plan de Desarrollo. 
Cuadro No. $6^{\mathrm{a}}$

PARTICIPACION DEL SITUADO FISCAL DEL SECTOR EDUCATIVO EN EL P.I.B.

\begin{tabular}{|c|c|c|c|c|c|c|c|c|c|}
\hline & 1990 & 1991 & 1992 & 1993 & 1994 & 1995 & 1996 & 1997 & 1998 \\
\hline $\begin{array}{l}\text { \$CORRIENTES } \\
\text { Situado Fiscal }\end{array}$ & 325.363 & 413.703 & 551.569 & 824.096 & 1.136 .344 & 1.389 .869 & 1.830 .342 & 2.228 .920 & 2.721 .960 \\
\hline Variación & & $27.2 \%$ & $33.3 \%$ & $49.4 \%$ & $37.9 \%$ & $22.3 \%$ & $31.7 \%$ & $21.8 \%$ & $22.1 \%$ \\
\hline $\begin{array}{l}\text { PIB } \\
\text { Variación }\end{array}$ & 20.228 .122 & $\begin{array}{r}26.106 .698 \\
291 \%\end{array}$ & $\begin{array}{r}33.143 .590 \\
27.0 \%\end{array}$ & $\begin{array}{r}41.986 .492 \\
26.7 \%\end{array}$ & $\begin{array}{r}52.796 .733 \\
25.7 \%\end{array}$ & $\begin{array}{r}65.643 .102 \\
24.3 \%\end{array}$ & $\begin{array}{r}80.752 .687 \\
230 \%\end{array}$ & $\begin{array}{r}98.054 .071 \\
21.4 \%\end{array}$ & 119.277.679 \\
\hline $\begin{array}{l}\text { Variación } \\
\text { Situado / PIB } \\
\text { \$CONSTANTES (94) }\end{array}$ & & $\begin{array}{r}29.1 \% \\
1.6 \%\end{array}$ & $\begin{array}{r}27.0 \% \\
1.6 \%\end{array}$ & $\begin{array}{r}26.7 \% \\
1.7 \%\end{array}$ & $\begin{array}{r}25.7 \% \\
2.0 \%\end{array}$ & $\begin{array}{r}24.3 \% \\
2.2 \%\end{array}$ & $\begin{array}{r}23.0 \% \\
2.1 \%\end{array}$ & $\begin{array}{r}21.4 \% \\
2.3 \%\end{array}$ & $\begin{array}{r}21.6 \% \\
2.3 \%\end{array}$ \\
\hline Situa & 725.396 & 728.964 & 794.872 & 980.6 & $1.136 .3^{3}$ & 1.187 .922 & 1.348. & 1.428 .081 & 1.529 .802 \\
\hline & & $0.5 \%$ & $9.0 \%$ & & & & & & $7.1 \%$ \\
\hline PIB & 45.098 .521 & 46.001 .216 & 47.763 .610 & 50.282 .594 & 52.796 .733 & 55.700 .545 & 58.842 .038 & 61.860 .673 & 65.720 .728 \\
\hline & & & & & & $5.5 \%$ & & $5.1 \%$ & $6.2 \%$ \\
\hline Situado / PIB & & $1.6 \%$ & $1.6 \%$ & $1.7 \%$ & $2.0 \%$ & $2.2 \%$ & $2.1 \%$ & $2.3 \%$ & $2.3 \%$ \\
\hline
\end{tabular}

Fuente: DNP - UDT 


\section{Cuadro No. 7}

\section{PLAN DE DESARROLLO EDUCATIVO 1995- 1998 TOTAL PROGRAMAS DE INVERSION NIVEL CENTRAL Y ENTIDADES TERRITORIALES}

\section{PROGRAMAS}

1. EDUCACION PREESCOLAR

1.1 Mejoramiento de la calidad 1.2 Subsidios para infraestructura 1.3 Subsidios para la Asistencia

\section{EDUCACION BASICA}

2.1 Mejoramiento de la calidad 2.2 Subsidios para infraestructura 2.3 Subsidios para la Asistencia 2.4 Desarrollo Institucional

TOTAL PROG. NUEVOS PREEESC. Y ED. BASICA TOTAL PROG. ANTIGUOS PREESC. $Y$ ED. BASICA

\section{EDUCACION SUPERIOR}

3.1 Programas nuevos de Créditos educativos 3.2 Fortalecimiento institucional, programas de Universidades y programas antiguos de crédito

\section{OPORTUNIDADES A JOVENES}

\subsection{Programa Recrear}

4.2 Talentos Deportivos y Artísticos

4.3 Programas de Desarrollo para la Juventud

TOTAL PROGRAMAS NUEVOS PARA JOVENES TOTAL PROGRAMAS ANTIGUOS PARA JOVENES

TOTAL SECTOR EDUCATIVO

(Millones de pesos de 1994)

\begin{tabular}{r|r|r|r|r|}
\multicolumn{1}{|c|}{1995} & \multicolumn{1}{|c|}{1996} & \multicolumn{1}{|c|}{1997} & \multicolumn{1}{c|}{1998} & \multicolumn{1}{c|}{ Total } \\
30.934 & 35.901 & 35.901 & 35.901 & 138.637 \\
2.110 & 2.073 & 2.073 & 2.073 & 8.329 \\
17.385 & 20.403 & 20.403 & 20.403 & 78.594 \\
11.439 & 13.425 & 13.425 & 13.425 & 51.714 \\
& & & & \\
89.519 & 231.885 & 275.642 & 283.501 & 880.548 \\
15.671 & 67.324 & 66.930 & 66.924 & 216.849 \\
14.842 & 106.978 & 106.978 & 60.407 & 289.205 \\
17.418 & 40.866 & 76.822 & 134.632 & 269.738 \\
41.589 & 16.718 & 24.911 & 21.538 & 104.756 \\
& & & & \\
120.453 & 267.786 & 311.543 & 319.402 & 1.019 .185 \\
36.060 & 38.838 & 56.891 & 35.770 & 167.559 \\
& & & & \\
88.894 & 110.908 & 111.269 & 121.075 & 432.146 \\
& & & & \\
5.398 & 27.412 & 27.773 & 37.579 & 98.161 \\
83.496 & 83.496 & 83.496 & 83.496 & 333.985 \\
& & & & \\
7.321 & 10.770 & 12.390 & 13.110 & 43.591 \\
1.375 & 3.600 & 4.500 & 4.500 & 13.975 \\
450 & 720 & 1.440 & 2.160 & 4.770 \\
2.982 & 3.500 & 3.500 & 3.500 & 13.482 \\
4.807 & 7.280 & 9.440 & 10.160 & 32.227 \\
2.514 & 2.950 & 2.950 & 2.950 & 11.364 \\
252.728 & 428.302 & 492.093 & 489.357 & 1.662 .480 \\
& & & &
\end{tabular}


Cuadro No. 7a

FUENTES DE FINANCIACIÓN PLAN DE DESARROLLO EDUCATIVO 1995-1998 Millones de pesos (1994)

\begin{tabular}{|c|c|c|c|c|c|c|}
\hline \multirow[t]{2}{*}{ PROGRAMAS } & \multicolumn{3}{|c|}{1995} & \multicolumn{3}{|c|}{1996} \\
\hline & $\begin{array}{l}\text { Aporte } \\
\text { Nacional }\end{array}$ & $\begin{array}{l}\text { Aporte } \\
\text { Territorial }\end{array}$ & $\begin{array}{l}\text { Crédito a } \\
\text { Dpto. y Mun. }\end{array}$ & $\begin{array}{l}\text { Aporte } \\
\text { Nacional }\end{array}$ & $\begin{array}{l}\text { Aporte } \\
\text { Territorial }\end{array}$ & $\begin{array}{l}\text { Crédito a } \\
\text { Dpto. y } \\
\text { Mun. }\end{array}$ \\
\hline \multicolumn{7}{|l|}{ 1. EDUCACION PREESCOLAR } \\
\hline 1.1 Mejoramiento de la calidad & 1.688 & 422 & & 1.658 & 415 & \\
\hline 1.2 Subsidios para infraestructura & 5.215 & 3.477 & 8.692 & 6.121 & 4.081 & 10.202 \\
\hline 1.3 Subsidios para la Asistencia & 9.151 & 2.288 & & 10.740 & 2.685 & \\
\hline Subtotal & 16.055 & 6.187 & 8.692 & 18.519 & 7.180 & 10.202 \\
\hline \multicolumn{7}{|l|}{ 2. EDUCACION BASICA } \\
\hline & & & & $\mathrm{C}$ & & \\
\hline 2.1 Mejoramiento de la calidad & 13.963 & 1.708 & & 57.170 & 10.154 & \\
\hline 2.2 Infraestructura & 4.453 & 2.968 & 7.421 & 29.407 & 24.082 & 53.489 \\
\hline 2.3 Subsidios & 13.934 & 3.484 & 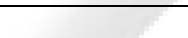 & 32.693 & 8.173 & \\
\hline 2.4 Desarrollo Institucional & 29.3245 & 12.265 & +2 & 4.453 & 12.265 & \\
\hline Subtotal & 61.674 & 20.424 & 7.421 & 123.722 & 54.674 & 53.489 \\
\hline Prog Antiaunc Prencs Y Fd Rácica & 36060 & & & 38838 & 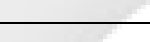 & \\
\hline Total Prog. Antiguos Preesc. y Ed. Básica & 113.789 & 26.611 & 16.113 & $\begin{array}{r}0.000 \\
181.079 \\
\end{array}$ & 61.855 & 63.691 \\
\hline & & & 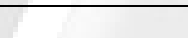 & & & \\
\hline \multicolumn{7}{|l|}{ 3. EDUCACION SUPERIOR } \\
\hline & & & & & & \\
\hline 3.1 Programas nuevos de Créditos educativos & 5.938 & & & 27.412 & & ב \\
\hline $\begin{array}{l}\text { 3.2 Fortalecimiento institucional, programas de } \\
\text { Universidades y programas antiguos de crédito }\end{array}$ & 83.496 & & & 83.496 & & \\
\hline TOTAL EDUCACIÓN SUPERIOR & 88.894 & & & 110.908 & & \\
\hline \multirow{2}{*}{\multicolumn{7}{|c|}{ 4. OPORTUNIDADES A JOVENES }} \\
\hline & & & & & & \\
\hline 4.1 Programa RECREAR & 1.100 & 275 & & 2.880 & 720 & \\
\hline 4.2 Talentos Deportivos y Artísticos & 360 & 90 & & 576 & 144 & \\
\hline 4.3 Programas de Desarrollo para la Juventud & 2.982 & & & 3.500 & & \\
\hline 4.4 Programas antiguos para jóvenes & 2.514 & & & 2.950 & & \\
\hline TOTAL PROGRAMAS DE JUVENTUD & 6.956 & 365 & & 9906 & 864 & \\
\hline TOTAL SECTOR EDUCATIVO & 209.638 & 26.976 & 16.113 & 301.893 & 62.719 & 63.691 \\
\hline Total Nacional + territorial + crédito & & 252.727 & & & 428302 & \\
\hline
\end{tabular}


Cuadro No. 7a.

FUENTES DE FINANCIACIÓN PLAN DE DESARROLLO EDUCATIVO 1995-1998

Millones de pesos (1994)

PROGRAMAS
1. EDUCACION PREESCOLAR

1.1 Mejoramiento de la calidad 1.2 Subsidios para infraestructura 1.3 Subsidios para la Asistencia

Subtotal

\section{EDUCACION BASICA}

2.1 Mejoramiento de la calidad

2.2 Infraestructura

2.3 Subsidios

2.4 Desarrollo Institucional

Subtotal

Prog. Antiguos Preesc. Y Ed. Básica Total Prog. Antiguos Preesc. y Ed. Básica

\section{EDUCACION SUPERIOR}

3.1 Programas nuevos de Créditos educativos 3.2 Fortalecimiento institucional, programas de Universidades y programas antiguos de crédito

TOTAL EDUCACIÓN SUPERIOR

\section{OPORTUNIDADES A JOVENES}

\subsection{Programa RECREAR}

4.2 Talentos Deportivos y Artísticos

4.3 Programas de Desarrollo para la Juventud

4.4 Programas antiguos para jóvenes

TOTAL PROGRAMAS DE JUVENTUD

TOTAL SECTOR EDUCATIVO

Total Nacional + territorial + crédito

\begin{tabular}{|c|c|c|c|c|c|}
\hline \multirow[b]{2}{*}{$\begin{array}{l}\text { Aporte } \\
\text { Nacional }\end{array}$} & \multicolumn{2}{|l|}{1997} & \multicolumn{3}{|c|}{1998} \\
\hline & $\begin{array}{l}\text { Aporte } \\
\text { Territorial }\end{array}$ & $\begin{array}{c}\text { Crédito a } \\
\text { Dpto. y Mun. }\end{array}$ & $\begin{array}{c}\text { Aporte } \\
\text { Nacional }\end{array}$ & $\begin{array}{c}\text { Aporte } \\
\text { Territorial }\end{array}$ & $\begin{array}{c}\text { Crédito a } \\
\text { Dpto. y Mun. }\end{array}$ \\
\hline 1.658 & 415 & & 1.658 & 415 & \\
\hline 6.121 & 4.081 & 10.202 & 6.121 & 4.081 & 10.202 \\
\hline 10.740 & 2.685 & & 10.740 & 2.685 & \\
\hline 18.519 & 7.180 & 10.202 & 18.519 & 7.180 & 10.202 \\
\hline 56.995 & 9.935 & & 56.970 & 9.954 & \\
\hline 29.407 & 24.082 & 53.489 & 16.832 & 13.371 & 30.204 \\
\hline 42.925 & 33.897 & & 68.329 & 66.303 & \\
\hline 12.647 & 12.265 & & 9.274 & 12.265 & \\
\hline 141.973 & 80.179 & 53.489 & 151.405 & 101.893 & 30.2049 \\
\hline 56.890 & & & 35.770 & & \\
\hline 217.383 & 87.359 & 63.691 & 205.694 & 109.073 & 40.405 \\
\hline 27.773 & & & 37.579 & & \\
\hline 83.496 & & & 83.496 & & \\
\hline 111.269 & & & 121.075 & & \\
\hline 3.600 & 900 & & 3.600 & 900 & \\
\hline 1.152 & 288 & & 1.728 & 432 & \\
\hline 3.500 & & & 3.500 & & \\
\hline 2.950 & & & 2.950 & & \\
\hline 11.202 & 1.188 & & 11.778 & 1.332 & \\
\hline 339.854 & 88.547 & 63.691 & 338.547 & 110.405 & 40.405 \\
\hline & 492.092 & & & 489.357 & \\
\hline
\end{tabular}


3. Mejorar significativamente la calidad de la Educación Básica. Con este fin se ampliará gradualmente la jornada real escolar de 3.5 a 6 horas diarias, se mejorarán progresivamente las condiciones salariales de los docentes y, con la participación de los municipios y del nivel central, se dotará con textos escolares a todos los estudiantes de establecimientos oficiales y se pondrán en funcionamiento aproximadamente 2.100 bibliotecas y centros de recursos educativos (ver cuadro No, 8).

4. Mejorar la equidad del sistema educativo, facilitando el acceso y permanencia de estudiantes de escasos recursos en la Educación Básica, distribuyendo los costos de la Educación Superior entre los alumnos según sus capacidades económicas, y facilitando el acceso a este nivel de estudiantes meritorios de bajos recursos, procedentes de todas las regiones del país. Con este fin se otorgarán subsidios a aproximadamente 1.600.000 estudiantes pobres y se apoyará a madres jefes de hogar en el pago de los costos educativos con un monto de $\$ 31.000$ millones. Se ofrecerán 180.000 nuevos créditos educativos para Educación Superior, lo que representa una inversión de $\$ 82.000$ millones y un cubrimiento adicional del 30\% de la matrícula proyectada para 1998.

5. Mejorar la calidad de las instituciones de Educación Superior, fomentando la acreditación y fortaleciendo la infraestructura científica y tecnológica, y la capacidad de gestión y administración de las universidades estatales. Con el fin de mejorar la capacidad investigativa de las instituciones educativas en este nivel, se otorgarán más de 600 becascrédito, hasta por $\$ 34.000$ millones.

6. Ampliar las oportunidades educativas, culturales y recreativas para la población, especialmente para los jóvenes más pobres, mediante la utilización más eficiente de los recursos que los distintos sectores destinan a la juventud y la asignación de \$31.000 millones adicionales.

En 1998, el gasto público educativo alcanzará una participación de $4.88 \%$ del PIB, lo que representa un aumento de 1.81 puntos con relación a 1993. El gasto entre los distintos niveles se distribuirá así: 33\% para preescolar y primaria, 29\% para la secundaria y $13 \%$ para la Educación Superior.

\section{Cuadro No. 8}

\section{PLAN DE DESARROLLO EDUCATIVO 1995-1998 METAS FISICAS}

PROGRAMAS
1. EDUCACION PREESCOLAR
1.1 Proyectos educativos exitosos apoyados
1.2 Educación activa
Docentes con guías pedagógicas
Alumnos de primaria con textos
Alumnos de secundaria con textos
1.3 Logro
Innovaciones para identificar y apoyar planteles
Planteles con Revista Alegría de Enseñar
Docentes capacitados (1 a 3 grado)
Planteles con ambiente aula mejorado
1.4 Cualificación del Preescolar
Docentes preescolar capacitados
Grados de preescolar con útiles

\begin{tabular}{r|r|r|r|r|}
\hline 1995 & \multicolumn{1}{|c|}{1996} & \multicolumn{1}{|c|}{1997} & \multicolumn{1}{c|}{1998} & \multicolumn{1}{c|}{ Total } \\
& 200 & 200 & 200 & 600 \\
& & & & \\
& 245.000 & 245.000 & 245.000 & 735.000 \\
437.695 & 1.438 .091 & 1.362107 & 1.362 .107 & 4.600 .000 \\
113.776 & 875.242 & 855.491 & 855.491 & 2.700 .000 \\
& & & & \\
23 & 50 & 50 & 50 & 173 \\
40.237 & 40.237 & 40.237 & 40.237 & 160.948 \\
17.839 & 27.101 & 24.004 & 24.004 & 92.948 \\
& 13.412 & 13.412 & 13.412 & 40.236 \\
& & & & \\
2.476 & 2.746 & 2.746 & 2.746 & 10.714 \\
2.537 & 2.997 & 2.540 & 2.540 & 10.714 \\
& & & & \\
& & & &
\end{tabular}




\subsection{Tiempo de Aprendizaje}

Centros de Recursos Educativos Municipales - CREM

equipados

\subsection{Evaluación}

Alumnos seleccionados para aplicación de pruebas de logro

\section{ORGANIZACIÓN}

\subsection{Institución Escolar Básica}

Instituciones Escolares Básicas capacitadas en gestión,

Sistema de información y sistema presupuestal y contable

\subsection{Organización Educativa Municipal}

Municipios capacitados en gestión, sistema de información, Sistema presupuestal y contable y en proyectos educativos Institucionales PEI

\subsection{Departamento}

Departamento y Distritos capacitados en sistema de información, sistema presupuestal y contable y en

Proyectos educativos institucionales PEI

\section{ASIGNACION}

\subsection{Subsidios Ampliación Oferta}

Cupos nuevos preescolar por ampliación infraestructura Cupos nuevos primaria por ampliación infraestructura

Cupos nuevos secundaria por ampliación infraestructura

\subsection{Subsidio Permanencia y Asistencia}

Número subsidios alumnos de preescolar

Número de subsidios alumnos de primaria

Beneficiarios bono escolar primaria-Red Solidaridad

Becas secundaria PACES

\section{EDUCACION SUPERIOR}

Créditos educativos otorgados

\section{OPORTUNIDADES A JOVENES}

Beneficiarios de programas recreativos

Beneficiarios del programa talentos deportivos-artísticos

\begin{tabular}{|c|c|c|c|c|}
\hline & 707 & 707 & 707 & 2.121 \\
\hline 50.000 & 55.000 & 55.000 & 2.160 & 215.000 \\
\hline 2.650 & 2.650 & 2.650 & 2.650 & 10.600 \\
\hline 261 & 261 & 261 & 261 & 1.044 \\
\hline 9 & 9 & 9 & 9 & 36 \\
\hline 76.687 & 103.313 & 90.000 & 90.000 & 360.000 \\
\hline 40.474 & 53.526 & 47.000 & 47.000 & 188.000 \\
\hline 23.000 & 257.500 & 257.500 & 123.600 & 661.600 \\
\hline 152.522 & 179.000 & 179.000 & 179.000 & 689.522 \\
\hline 64.916 & 116.178 & 130.673 & 150.000 & 461.767 \\
\hline 70.000 & 140.000 & 150.000 & 150.000 & 510.000 \\
\hline 80.545 & 140.545 & 200.545 & 340.000 & 761.635 \\
\hline 35.598 & 144.159 & 177.789 & 278.208 & 635.754 \\
\hline $\begin{array}{r}122 \\
\end{array}$ & 400 & 400 & 400 & 1.322 \\
\hline 1.500 & 3.000 & 6.000 & 9.000 & 19.500 \\
\hline
\end{tabular}

\section{ESTRATEGIAS Y PROGRAMAS PARA UNIVERSALIZAR LA EDUCACIÓN BÁSICA}

Para el cumplimiento de los objetivos de este plan, se proponen estrategias dirigidas a transformar el modelo pedagógico, organizacional y de asignación de recursos del sector, así como los instrumentos para favorecer la equidad. Estas estrategias son: (i) una institución educativa centrada en el estudiante, como instrumento básico para mejorar la calidad; (ii) un nuevo modelo de organización administrativa del sector, centrado en la organización escolar; (iii) un sistema de asignación de recursos vinculado a resultados; y (iv) una mayor cobertura y equidad.

\section{A. Mejorar la calidad: una institución educativa centrada en el aprendizaje}

Para lograr una educación de calidad se requiere que las instituciones educativas cuenten con una misión claramente definida, unos objetivos congruentes con la misión y unas estrategias y programas específicos; todo esto debe estar centrado en las necesidades educativas del estudiante. Para ello, se pondrán en marcha los siguientes programas: 


\section{Un Proyecto Educativo Institucional (PEI) en cada establecimiento}

EI PEI es un plan anual de desarrollo administrativo y pedagógico del establecimiento, cuyo propósito fundamental es mejorar la calidad de la educación, en función de las necesidades educativas del estudiante. A partir de un diagnóstico se formulan, en cada caso, objetivos, metas y programas concretos, factibles y evaluables. En su elaboración participa la comunidad educativa y es adoptado por el Gobierno Escolar, como organismo que garantiza la participación democrática de todos los estamentos de la comunidad educativa (rector, representantes de los docentes, estudiantes, padres de familia y exalumnos) en la dirección de las instituciones.

Serán prioritarias en cada PEI las metas relacionadas con los logros educativos esperados de los estudiantes, así como con la creación de un ambiente escolar propicio para el desarrollo personal, ético y social de los educandos. Se promoverá la elaboración de proyectos educativos que fomenten el desarrollo de valores de convivencia, participación, solidaridad y conservación del medio ambiente.

En 1997 todas las instituciones escolares deberán contar con un PEI. La asistencia técnica para la elaboración de los proyectos será responsabilidad de los departamentos, con el apoyo técnico del Ministerio de Educación (MEN), quien premiará anualmente a 200 instituciones educativas que ejecuten los mejores PEI.

\section{Promoción de la educación activa}

Con el fin de superar el carácter pasivo de la enseñanza tradicional, se promoverá la transformación de los sistemas pedagógicos rutinarios en sistemas activos, de tal manera que el alumno participe y pueda organizar efectivamente su propio aprendizaje.

Para lograr lo anterior la nación cofinanciará la adquisición por parte de los municipios y planteles, de materiales educativos que fomenten el autoaprendizaje de los alumnos y el trabajo en grupo. De la misma manera, el MEN diseñará y distribuirá materiales dirigidos a los docentes, encaminados a actualizarlos en los contenidos curriculares y en las distintas metodologías pedagógicas, con énfasis en la enseñanza activa.

El Ministerio de Educación promoverá la creación de una corporación mixta que financie proyectos de investigación y desarrollo de productos y procesos pedagógicos innovadores, que puedan ser utilizados masivamente por docentes y estudiantes, dentro de un concepto de educación activa.

\section{Fortalecimiento preescolar}

Como es sabido, deficiencias nutricionales y de estimulación en la etapa preescolar disminuyen de forma significativa las posibilidades de aprendizaje de los niños. Con el fin de mejorar las condiciones de entrada de los niños al sistema educativo, se pondrán en marcha acciones interinstitucionales que permitan mejorar la atención educativa de más de 800.000 niños beneficiarios de los Hogares Comunitarios de Bienestar y de otros programas de atención a los menores de cinco años.

Además se ampliará la capacidad del sistema educativo para proporcionar un grado de educación preescolar, mediante la creación de 300.000 cupos adicionales y la realización de convenios entre los municipios y organizaciones no gubernamentales para mejorar la cobertura y la calidad de la atención en este nivel. Con tal propósito se otorgarán subsidios a aproximadamente un millón de niños de bajos recursos. 


\section{Mejores logros en las áreas básicas}

La Educación Básica deberá buscar que los alumnos desarrollen los valores, conocimientos y destrezas requeridas para participar activa y productivamente en la sociedad $^{6}$. Para reducir el fracaso escolar se aumentará la retención en las instituciones, se mejorarán sustancialmente los logros de los estudiantes en las pruebas de rendimiento y se promoverá el aprendizaje de la lectura, la escritura y las matemáticas en los tres primeros grados. Con este fin, los programas de dotación procurarán que cada estudiante tenga por lo menos un texto de matemáticas y uno de lectura.

5. Aumento del tiempo dedicado al aprendizaje

El aumento del número de días del calendario escolar, así como el número de horas diarias empleadas en actividades exclusivas de aprendizaje, serán una prioridad para garantizar el logro de los conocimientos y habilidades básicos, además de generar posibilidades para que los estudiantes aprendan una segunda lengua.

En la actualidad el $52.6 \%$ de los alumnos asisten a establecimientos con una sola jornada y tan sólo el $11 \%$ de los establecimientos requieren de ampliación de infraestructura (Cuadro No. 9). La extensión de la jornada escolar en las instituciones de Educación Básica será gradual y estará sujeta a la decisión del Gobierno Escolar, de acuerdo con las metas del PEI. Esta ampliación será posible gracias a medidas como el incremento progresivo de 3.5 a 6 horas de clase, y a actividades educativas en los espacios escolares libres, en instalaciones deportivas y culturales, en los Centros de Recursos Educativos Municipales ${ }^{7}$, así como en laboratorios de idiomas y de informática.

\section{Dotación de textos, bibliotecas y material educativo}

A través de este programa se canalizarán recursos de cofinanciación a los municipios y las instituciones educativas para la adquisición de textos, así como para la dotación de bibliotecas, laboratorios y, en general, centros de recursos educativos que presten servicio a uno o más planteles. Se espera, así, que las crecientes transferencias a los municipios, orientadas a la educación, se dirijan en gran medida a mejorar la dotación de las instituciones educativas en sus jurisdicciones.

\footnotetext{
${ }^{6}$ Comprensión de lectura, razonamiento lógico, operaciones aritméticas, solución de problemas, expresión oral y escrita, interpretación de los mensajes de los medios de comunicación, así como la participación en el diseño y ejecución de trabajos de grupo.

${ }^{7}$ Los Centro de Recursos son instalaciones municipales, concebidas para atender varios establecimientos educativos y están dotados con ayudas educativas, equipos, bibliotecas y laboratorios. 
Cuadro No. 9

INDICADORES SEGÚN JORNADAS EN EL SECTOR OFICIAL 1991

\begin{tabular}{|c|c|c|c|c|c|c|c|c|c|}
\hline & Establecimientos & Alumnos & \%Alumnos & Docentes & \%Docentes & Grupos & $\begin{array}{l}\text { Alumnos/ } \\
\text { Docentes }\end{array}$ & $\begin{array}{c}\text { Alumnos/ } \\
\text { Grupo }\end{array}$ & $\begin{array}{c}\text { Docentes } \\
\text { Grupo }\end{array}$ \\
\hline Completa y adicional & 9.514 & 623.064 & $12.9 \%$ & 29.569 & $12.1 \%$ & 18.889 & 21.07 & 32.99 & 1.57 \\
\hline Mañana & 21.153 & 1.743 .088 & $36.2 \%$ & 91.319 & $37.4 \%$ & 62.525 & 19.9 & 27.88 & 1.46 \\
\hline Tarde & 547 & 105.3471 & $2.2 \%$ & 5.853 & $2.4 \%$ & 4.100 & 18.02 & 25.72 & 1.43 \\
\hline Noche & 199 & 63.022 & $1.3 \%$ & 3.075 & $1.3 \%$ & 3.300 & 20.49 & 19.10 & 0.93 \\
\hline Con una jornada & 31.413 & 2.534 .645 & $52.6 \%$ & 129.816 & $53.1 \%$ & 88.814 & 19.52 & 28.54 & 1.46 \\
\hline Mañana tarde & 3.747 & 1.900 .223 & $39.4 \%$ & 92.473 & $37.9 \%$ & 61.599 & 20.55 & 30.85 & 1.50 \\
\hline Mañana noche & 67 & 38.767 & $0.8 \%$ & 2.470 & $1.0 \%$ & 2.083 & 15.70 & 18.61 & 1.19 \\
\hline Mañana tarde noche & 179 & 243.486 & $5.1 \%$ & 13.608 & $5.6 \%$ & 10.553 & 17.89 & 23.07 & 1.29 \\
\hline Tarde noche & 24 & 16.496 & $0.3 \%$ & 1.103 & $0.5 \%$ & 790 & 14.96 & 20.88 & 1.40 \\
\hline Con dos o más jornadas & 4.017 & 2.198.972 & $45.6 \%$ & 109.654 & $44.9 \%$ & 75.025 & 20.05 & 29.31 & 1.46 \\
\hline Otras modalidades & 2.52 & 84.732 & $1.8 \%$ & 4.838 & $2.0 \%$ & 3.069 & 17.51 & 27.61 & 1.58 \\
\hline TOTAL & 35.682 & 4.818 .349 & $100 \%$ & 244.308 & $100 \%$ & 166.908 & 19.72 & 28.87 & 1.46 \\
\hline
\end{tabular}

Fuente: MEN - Subdirección de Análisis y Desarrollo de la información 
EI MEN definirá los requisitos mínimos que deberá tener un plantel de Educación Básica, incluyendo los soportes de la actividad pedagógica, los que podrán compartir con otros establecimientos del municipio, de acuerdo con el número de estudiantes. Para cumplir estos requisitos, los planteles y los municipios tendrán acceso a recursos para la ampliación y renovación de la infraestructura, así como para su dotación.

\section{Mejor calificación de los docentes}

Se apoyarán prioritariamente los planes de capacitación que resulten de los PEI y se promoverá, conjuntamente con las instituciones de Educación Superior, una oferta educativa diversificada, orientada a elevar la capacidad de los docentes para responder a las necesidades de aprendizaje de los estudiantes.

El MEN, con el apoyo del Servicio Nacional de Pruebas, diseñará e implantará en 1995 el sistema de selección de aspirantes a la carrera docente y pondrá en marcha la evaluación de desempeño de los docentes, para efecto de la fijación de sus estímulos. Los docentes se verán beneficiados con el crecimiento real de sus salados, incremento que será gradual y asociado al tiempo trabajado y al rendimiento de los estudiantes.

\section{La evaluación pedagógica y el monitoreo}

Corresponderá a los docentes identificar cuáles son las mayores dificultades para el aprendizaje de cada estudiante y diseñar soluciones para garantizar la promoción escolar basada en niveles óptimos de logro. La evaluación institucional será responsabilidad del Gobierno Escolar, con base en los objetivos del PEI.

La evaluación externa se realizará a través de pruebas periódicas, hoy casi inexistentes, a una muestra nacional de estudiantes, para evaluar el rendimiento en las áreas básicas del currículo. Especial énfasis se otorgará al análisis de los factores que explican el rendimiento de los estudiantes, así como a la amplia difusión de los resultados de la evaluación.

Se establecerá el Examen de Estado de Educación Básica con el propósito de evaluar las aptitudes y competencias de los estudiantes en las áreas de lectura, expresión escrita, razonamiento lógico y solución de problemas. Por su parte, el MEN establecerá normas técnicas, evaluará las diferentes alternativas que en textos, material didáctico y otros recursos ofrece el mercado nacional e internacional, y formulará recomendaciones a los planteles y a los municipios para la adquisición de los materiales y medios educativos.

\section{B. Un nuevo modelo de organización educativa: la institución escolar, centro de la organización administrativa}

La institución escolar es la célula fundamental del sistema y debe garantizar la continuidad del proceso educativo del alumno ${ }^{8}$. Las principales instancias de la organización educativa deben servir, ante todo, a la institución escolar. Esta deberá contar con la autonomía y capacidad de operación necesaria para su funcionamiento óptimo, y para responder a los estudiantes, a los padres de familia y a la comunidad en general.

\footnotetext{
${ }^{8}$ Una institución escolar, según lo definido por la Ley 115 de 1994 en su articulo 138, debe contar, entre otros, con la infraestructura administrativa y pedagógica para ofrecer, por lo menos, un grado de preescolar y los nueve de educación básica.

Digitalizado por RED ACADEMICA
} 
Para el logro de esta nueva organización educativa se pondrán en marcha los siguientes programas:

\section{Implantación de la institución escolar básica}

Para garantizar la continuidad del proceso educativo, los establecimientos educativos oficiales deberán ofrecer mínimo un grado de preescolar y nueve grados de Educación Básica, directamente o a través de convenios con otros establecimientos. Estos acuerdos podrán darse entre entidades de diferente régimen, siempre y cuando respeten las leyes vigentes, y constituyan una sola entidad desde el punto de vista pedagógico y de administración docente.

EI MEN de acuerdo con los departamentos, y los departamentos de acuerdo con los municipios, diseñarán, aplicarán y darán seguimiento a este programa. Por su parte, el MEN levantará un inventario sistematizado de las formas administrativas que resulten, hará un estudio evaluativo anual de ellas y promocionará aquellas que demuestren ser exitosas.

\section{Implantación de la organización educativa municipal}

Todos los municipios del país contarán con una organización administrativa que les permita desarrollar eficiente y eficazmente su plan educativo.

Los municipios, con el apoyo de los departamentos y del MEN, se organizarán para cumplir sus funciones administrativas, como son la planificación, el mantenimiento del sistema de información, la administración del personal, la evaluación de gestión y la inspección y vigilancia de los establecimientos.

La organización educativa municipal apoyará a las instituciones en el diseño y dotación de los espacios, el suministro de los equipos y la adquisición de textos y materiales. Así mismo, proveerá directamente o a través de terceros, servicios comunes (laboratorios, bibliotecas, instalaciones deportivas y culturales) a planteles públicos o privados que no estén en capacidad de ofrecerlos.

\section{Implantación de la organización educativa departamental}

Es función primordial del departamento ofrecer asistencia técnica a los municipios para el desarrollo pedagógico, el desarrollo de los recursos humanos, el soporte administrativo para el manejo de los recursos financieros, la asignación del situado fiscal y la evaluación de la gestión municipal.

Para el ejercicio de tales funciones, el departamento deberá fortalecer la capacidad de monitoreo y evaluación de gestión de los planes municipales. El plan departamental contemplará el desarrollo de experiencias de descentralización realizadas conjuntamente con los municipios.

\section{Organización del Ministerio de Educación}

El Ministerio fortalecerá sus funciones de dirección, planificación, diseño, normatización, evaluación y seguimiento, y tendrá una unidad operativa de transición para impulsar la descentralización de la administración escolar, y para asesorar a los departamentos y municipios en el desempeño de sus competencias. 


\section{Un modelo de asignación de recursos vinculado a los resultados}

Esta es una estrategia dirigida a mejorar la eficiencia en términos administrativos y pedagógicos y tiene como instrumento la asignación de recursos en relación con la eficiencia y la calidad.

Se identificarán, fortalecerán y difundirán las experiencias administrativas y pedagógicas que hayan demostrado ser exitosas y cuyos costos estén al alcance de las instituciones escolares. Estas innovaciones se divulgarán, preferentemente, entre las instituciones que hayan alcanzado menores logros, mediante mecanismos especiales de asistencia técnica, con prioridad en aquellas regiones de menor desarrollo relativo en el campo de la educación.

Los subsidios estatales dedicados a promover la expansión y la calidad se distribuirán entre las instituciones escolares de acuerdo con los resultados obtenidos, medidos por los resultados de las pruebas de logro, la ampliación de la cobertura por aumento de eficiencia y los estudiantes promovidos. Se apoyará financieramente a 600 instituciones que muestren resultados exitosos. Además, se verificará que las transferencias municipales contemplen adecuadamente los aumentos proporcionales de cobertura y eficiencia.

\section{Hacia una mayor cobertura y equidad}

La Educación Básica, como un servicio público de carácter universal, debe buscar la equidad, tanto en las oportunidades de acceso como en la calidad. El Estado dará apoyo irrestricto a la Educación Básica y seguirá aportando recursos importantes que para 1998 serán equivalentes al $3.04 \%$ del PIB, para asegurar el crecimiento de la cobertura de este nivel.

Dadas las diferencias que aún persisten en el acceso a la educación, se pondrán en marcha los siguientes programas para mejorar la situación de los más pobres:

\section{Subsidios a estudiantes de escasos recursos}

Con este programa se busca ampliar las oportunidades de acceso a la Educación Básica para un mayor número de estudiantes de bajos recursos. Se hará mediante la contratación de este servicio con instituciones educativas privadas, solidarias o mixtas, que estén constituidas como organizaciones sin ánimo de lucro. Los subsidios se entregarán a las instituciones educativas contratadas en función de los estudiantes atendidos.

Con el fin de incentivar la oferta, también podrán entregarse planteles en administración a las fundaciones que participen en el programa. Igualmente se canalizarán recursos de crédito a instituciones privadas a través de la Financiera de Desarrollo Territorial, FINDETER.

\section{Bono escolar}

Para facilitar la permanencia de estudiantes de bajos recursos en los primeros grados de la Educación Básica, se entregarán, a través de la Red de Solidaridad Social, 150.000 subsidios a madres jefes de hogar cuyos hijos pequeños estén cursando primaria, dirigidos a apoyar la consecución de uniformes, libros y útiles escolares. 


\section{EDUCACIÓN MEDIA}

La Educación Media estará orientada a consolidar los conocimientos, habilidades y aptitudes desarrollados en la Educación Básica, permitiendo al estudiante, al mismo tiempo, profundizar en un campo del conocimiento, o en una actividad específica, de acuerdo con sus intereses y capacidades. El aumento de eficiencia y la expansión de la Educación Básica durante los próximos años, se traducirán en un aumento de cobertura de la educación media a partir de 1998.

Las instituciones educativas orientarán al egresado de la Educación Básica en lo relacionado con la continuación de sus estudios, en la Educación Media o en el sistema de educación laboral.

\section{LINEAMIENTOS PARA UNA POLÍTICA DE EDUCACIÓN SUPERIOR}

La política de Educación Superior se articulará alrededor del mejoramiento de la calidad de los programas, el acceso equitativo y el fortalecimiento de las instituciones, en el marco de la autonomía universitaria y de acuerdo con los lineamientos de este documento.

La acreditación constituye el instrumento fundamental para mejorar la calidad de los programas de Educación Superior. El Gobierno Nacional, conjuntamente con el Consejo Nacional de Educación Superior (CESU), dará las pautas para que la acreditación responda a criterios de excelencia. El Estado pondrá a disposición recursos financieros crecientes para la financiación de estudiantes, de proyectos y programas de investigación presentados por las instituciones acreditadas.

EI ICFES se consolidará como la institución técnica de apoyo y fomento a la Educación Superior, conjuntamente con el CESU. Además de mantener actualizado el sistema de indicadores de la Educación Superior y divulgar la información sobre la calidad de los programas, promoverá y adelantará las investigaciones que conduzcan al mejoramiento de la calidad y la eficiencia de las instituciones en este nivel. Igualmente apoyará la labor periódica de seguimiento y evaluación de los programas de las diferentes instituciones y facilitará, a instancias del CESU, el trabajo de los pares en la acreditación de los programas e instituciones.

Una ampliación adecuada de la oferta educativa y un acceso más equitativo a los cupos se conseguirá con la ampliación de créditos para el pago de los gastos educativos y sostenimiento para estudiantes meritorios de escasos recursos así como con mejoras institucionales que aseguren mayor eficiencia y promuevan que los costos educativos se distribuyan entre los alumnos de acuerdo con sus capacidades económicas y las de sus familias.

Las instituciones estatales de Educación Superior deberán enfrentar los retos que la modernización del país les plantea, adecuando sus sistemas financiero y administrativo a las recomendaciones que produzca la Misión Nacional para la Modernización de la Universidad Pública. Merecerá especial atención la constitución de un Sistema Universitario Estatal que permita que las universidades aprovechen las ventajas comparativas de otras instituciones dentro de una red de recursos y servicios. 
El Estado garantizará el cubrimiento de los costos de funcionamiento de las universidades estatales, conforme a los presupuestos de rentas y gastos vigentes a partir de 1993, pero se corregirá la asignación inercial de recursos, de manera que responda a criterios de calidad, cobertura y desarrollo institucional. Además, se estimulará financieramente a las instituciones que generen sus propios recursos.

\section{OPORTUNIDADES PARA LA EDUCACIÓN PERMANENTE}

La educación es un proceso permanente que no se agota en los establecimientos educativos. Por ello se buscará brindar oportunidades para el aprendizaje continuo a personas de todas las edades, según sus necesidades. Estas oportunidades podrán ser organizadas o informales y en su desarrollo intervendrán actores diversos, internos y externos al sector educativo.

\section{A. Oportunidades para los jóvenes}

Los problemas que afectan a la población juvenil ameritan el diseño de una estrategia específica dirigida a ampliar las oportunidades para su desarrollo personal y social, basada en la coordinación de los distintos organismos estatales. Esta coordinación deberá producir como resultado la utilización más eficiente de los recursos que a nivel sectorial se destinan a la juventud.

A través de programas dirigidos a la población juvenil se buscará promover su participación y organización, estimular sus iniciativas hacia la paz y la convivencia, mejorar los esfuerzos de prevención integral y promoción de estilos sanos de vida. Se actualizarán, además, normas relativas a la juventud.

\section{Una segunda oportunidad para los jóvenes que abandonan la Educación Básica}

Con el fin de "rescatar" a los desertores del sistema educativo y motivarlos a que concluyan la Educación básica, se reorientarán los actuales programas de educación de jóvenes y adultos para fomentar el estudio independiente y en grupo, mediante estrategias educativas flexibles, con el apoyo de los medios de comunicación, particularmente la radio y la televisión.

\section{Capacitación laboral para los jóvenes}

Se conformará una red de educación media técnica, formación profesional y educación laboral, constituida por las entidades que ofrecen educación para el trabajo ${ }^{9}$, las cuales se articularán buscando la complementariedad con base en sus ventajas comparativas, en aspectos tales como la planeación educativa, la organización administrativa, la formación y selección de docentes, la concertación con el sector productivo, la orientación hacia la vida laboral y el seguimiento y la evaluación.

\footnotetext{
9 (i) SENA, cuya contribución se centrará en la metodología de modularización de planes y programas de estudio, la orientación ocupacional, el sistema de planeación y las metodologías de formación; (ii) el MEN, como responsable de la regulación y control de la oferta de la educación media y de la orientación curricular y de la política de juventud; (iii) el ICFES por su papel respecto a la oferta de formación técnica y tecnológica de nivel superior; (iv) las instituciones privadas de educación no formal; y (v) el sector productivo en general.

Digitalizado por RED ACADEMICA
} 
Con el fin de ampliar las oportunidades para la capacitación laboral de los jóvenes, el SENA incrementará la cobertura de sus programas de capacitación a 150.000 jóvenes, en horarios diurnos. El contrato de aprendizaje no será requisito para ingresar a estos cursos, y se apoyará con becas de sostenimiento a 80.000 jóvenes, con el fin de permitir dedicación exclusiva a la capacitación.

La capacitación laboral dará prioridad a tecnologías transversales que permitan al trabajador desempeñarse en distintos puestos de trabajo y en distintas ramas de actividad. Los cursos deberán fomentar la creatividad, la capacidad para tomar decisiones y trabajar en grupo, así como para seguir aprendiendo.

\section{Fomento a uso creativo del tiempo libre}

Se aumentará significativamente la participación y la práctica de la población juvenil en la recreación y el deporte, mediante programas de ampliación de la cobertura basados en la utilización programada y eficiente de la infraestructura estatal y privada. Para ello, se organizarán Centros de Servicios Deportivos administrados por los municipios directamente o a través de convenios con entidades particulares.

Adicionalmente, se promoverán, conjuntamente con la empresa privada, oportunidades para que los jóvenes gocen de privilegios en el acceso a eventos culturales y planes especiales de turismo.

\section{Estímulo a talentos deportivos y artísticos}

La Red de Solidaridad Social apoyará 9.000 jóvenes pobres entre 12 y 18 años con un subsidio-beca para sufragar costos de instrucción y práctica de actividades artísticas o deportivas en las cuales hayan demostrado capacidades excepcionales. Estos jóvenes deberán permanecer en el sistema educativo hasta la culminación de sus estudios. El programa se ejecutará a través del ICETEX y será cofinanciado con los municipios.

\section{B. Un medio educativo propicio para la educación permanente}

El Estado, en sus diferentes niveles de la administración, fomentará la oferta de oportunidades para que los ciudadanos participen ampliamente de la cultura. Para ello se establecerán redes nacionales y departamentales de bibliotecas y museos, una red nacional de centros de información para la juventud, y se apoyará la conformación de unidades móviles que lleven exposiciones, laboratorios, computadores, libros y otros materiales a pueblos y veredas. También se utilizarán eventos como festivales, ferias y carnavales como espacios educativos y oportunidades para dinamizar las culturas locales y regionales.

El Estado apoyará las instituciones que asumen el liderazgo en la producción de material radial y televisivo de interés público y velará porque se generen espacios para su difusión en los canales nacionales.

\section{RECOMENDACIONES}

El Ministerio de Educación Nacional y el Departamento Nacional de Planeación recomiendan al CONPES: 
1. Aprobar la política y los programas educativos presentados en este documento, que implican un avance sustancial en la concepción de la educación y en el rol de sus actores.

2. Solicitar al MEN la realización de foros, debates y campañas que generen una amplia movilización de la opinión alrededor de la calidad de la educación.

3. Solicitar al MEN que tome las medidas pertinentes para acelerar y consolidar el proceso de descentralización, y apoyar la transformación que a nivel departamental y municipal se requiere para la ejecución de las estrategias previstas en este documento.

4. Solicitar al MEN coordinar con las entidades territoriales y con las instituciones del Gobierno central, el desarrollo de los diferentes programas a que se refiere este documento. Conjuntamente con el DNP, adelantará las labores de monitoreo y seguimiento de los mismos.

5. Solicitar al MEN y al ICBF coordinar la atención educativa de los niños beneficiarios de los programas dirigidos a la población en edad preescolar.

6 Solicitar al MEN y al FIS desarrollar y difundir las metodologías de elaboración y evaluación de los proyectos de Educación Básica, Educación Superior, recreación, cultura y deporte, que se desarrollarán con recursos de cofinanciación de la Nación, y promover la presentación de proyectos por parte de los municipios.

7. Solicitar a FINDETER aplicar las líneas de crédito aprobadas para financiar infraestructura y dotación educativa en los municipios, las universidades y las instituciones privadas.

8. Solicitar al DNP, al MEN y al ICFES la elaboración de un documento sobre política y programas de Educación Superior, con base en los lineamientos presentados en el presente documento, y someterlo a consideración del CONPES antes del 31 de diciembre de 1994.

9. Solicitar al ICFES el diseño y la puesta en marcha del sistema de información para la Educación Superior y la Acreditación, apoyo al CESU en las tareas propias del proceso de acreditación y el desarrollo de los sistemas de fomento a la calidad de la Educación Superior propuestos en este documento.

10. Solicitar al MEN que con el apoyo del Servicio Nacional de Pruebas diseñe, aplique y divulgue los resultados de las pruebas de rendimiento que se realicen para evaluar la calidad de la educación.

11. Solicitar al MEN y al ICETEX diseñar los mecanismos de financiación internos y externos que permitan ampliar el número de sus beneficiarios, así como una mejor selección de los aspirantes a crédito educativo para Educación Superior.

12. Solicitar al SENA adelantar los diseños técnico-pedagógicos requeridos para la formación profesional de jóvenes que hayan completado al menos el noveno grado de Educación Básica, y ampliar la cobertura de los programas de capacitación dirigidos a la población joven, directamente o a través de centros especializados debidamente acreditados. 
13. Solicitar a los Ministerios de Educación y Comunicaciones diseñar un sistema de incentivos para las instituciones públicas y privadas que asuman un liderazgo en la producción de material radial y televisivo de naturaleza educativa. 